\title{
Size estimation and the size of the measuring unit'
}

H. RICHARD SCHIFFMAN

RUTGERS UNIVERSITY

\begin{abstract}
Size estimates of line drawings made in terms of a familiar and three unfamiliar units of measure, presented as line segments, and another response condition requiring the familiar units to be drawn from memory, were examined. The results were: (1) in general, there was an underestimation using a relatively small, unfamiliar unit of measure, and an overestimation using all other units of measure; (2) generally, the unit of measure enabling the most accurate estimates was the familiar unit; (3) estimates using the familiar unit in two response conditions were not essentially different. Problem
\end{abstract}

The concern in many perceptual studies is with magnitude estimation of a single stimulus rather than with a comparison of stimuli. In a number of such studies $\mathrm{S}$ is generally instructed to verbally respond in terms of a standard unit of measure, e.g., inches (Bolles \& Bailey, 1956; Churchill, 1962). A history of commerce with this unit of measure results in knowledge of the unit without repeated reference to the standard. However, does use of this familiar unit of measure enable more accurate estimation than use of unfamiliar units?

The present study was performed to examine this question and the relation between the unit of measure and the stimulus estimated.

\section{Method}

Twenty-one males from an introductory course in psychology served as the Ss. All were naive as to the content and purpose of the experiment.

The stimuli were three line drawings, $3.44,9.69$, and 19.44 in, painted on cards of poster board. The lines extended diagonally across the card. The units of measure used by $\mathrm{S}$ in making his estimates were line segments painted on $10-1 / 2$ by 11 in cards of poster board and were presented horizontally to $S$. The four units were segments $1 \mathrm{~cm}, 1 \mathrm{in}, 4 \mathrm{~cm}$, and 3 in. Another condition of responding was also used in which $\mathrm{S}$ was asked to estimate and verbally report, in inches, the length of the three stimuli. This verbally presented unit required an estimate with the inch drawn from memory. No information was given about the length of the units.

All Ss were individually tested. Each S estimated three stimuli using five units of measure totaling 15 size estimations. The presentation of the stimuli and the four line segment units of measure were randomized for each S. Presentation of the inch unit drawn from memory was always last.

Ss were told to estimate the length of the stimuli in terms of the line segments which were presented for each stimulus, i.e., "Estimate how many of the line segments are contained in the line." Ss were instructed to use fractions of a line segment if they wished. Results

Table 1 presents the means, standard deviations, and mean deviations (without regard to sign) of estimations from the physical size of the stimulus for the three stimuli estimated by the five units of measure. These latter two measures can serve as indicants of accuracy, i.e., the lower these values, the more accurate the unit of measure. (Though not in complete correspondence with each other, a linear correlation coefficient between these two measures was found to be $.937, p<.001$. However, the deviations were chosen to describe accuracy since they make use of the physical size of the stimuli and thus are a direct measure of accuracy.) An inspection of the deviations indicates that for the 9.69 and 19.44 in stimuli the smallest and largest units of measure resulted in the greatest deviations, reflecting least accuracy. The results for the same stimuli indicate greatest accuracy for the inch (memory) and the inch as a line segment, respectively. For the 3.44 in stimulus little differences in accuracy over the units were found. However, estimates made using the 3 in unit were the most accurate, followed by estimates made using the inch as a segment.

An examination of the mean estimates of the lengths of the three stimuli by the five units of measure indicates that use of a relatively small unit $(1 \mathrm{~cm})$ resulted in an underestimation of the lengths of the three stimuli. This underestimation increased directly with the length of the stimuli. All other units (with the exception of the $4 \mathrm{~cm}$ unit for the 3.44 in stimulus) resulted in overestimations. An analysis of variance yielded significant main effects due to Units $(F=4.10, d f=4 / 200, p<.01)$, to Stimuli $(F=129.78, d f=2 / 200, p<.001)$, to Subjects

Table 1. Means, Standard Deviations, and Mean Deviations in Absolute Values from the Physical Size of the Stimuli, for all Stimuli by all Units of Measure

\begin{tabular}{|c|c|c|c|c|c|}
\hline & \multicolumn{5}{|c|}{ Units of Measure } \\
\hline & $1 \mathrm{~cm}$ & 1 in & $\begin{array}{c}1 \text { in } \\
\text { (memory) }\end{array}$ & $4 \mathrm{~cm}$ & 3 in \\
\hline $\begin{array}{l}3.44 \text { In Stimulus Means } \\
\text { Standard Deviations } \\
\text { Mean Deviations }\end{array}$ & $\begin{array}{l}3.167 \\
0.727 \\
0.642\end{array}$ & $\begin{array}{l}3.607 \\
0.447 \\
0.339\end{array}$ & $\begin{array}{l}3.774 \\
0.749 \\
0.675\end{array}$ & $\begin{array}{l}3.194 \\
0.438 \\
0.458\end{array}$ & $\begin{array}{l}3.582 \\
0.300 \\
0.315\end{array}$ \\
\hline $\begin{array}{l}9.69 \text { In Stimulus Means } \\
\text { Standard Deviations } \\
\text { Mean Deviations }\end{array}$ & $\begin{array}{l}7.9,17 \\
2.394 \\
2.611\end{array}$ & $\begin{array}{r}10.024 \\
2.118 \\
1.240\end{array}$ & $\begin{array}{r}10.643 \\
1.086 \\
1.084\end{array}$ & $\begin{array}{r}10.140 \\
1.390 \\
1.130\end{array}$ & $\begin{array}{r}12.627 \\
3.458 \\
3.028\end{array}$ \\
\hline $\begin{array}{c}19.44 \text { In Stimulus Means } \\
\text { Standard Deviations } \\
\text { Mean Deviations }\end{array}$ & $\begin{array}{r}14.569 \\
4.134 \\
5.445\end{array}$ & $\begin{array}{r}19.714 \\
4.671 \\
3.194\end{array}$ & $\begin{array}{r}21.524 \\
5.511 \\
3.609\end{array}$ & $\begin{array}{r}20.986 \\
6.161 \\
4.184\end{array}$ & $\begin{array}{r}25.893 \\
7.964 \\
6.727\end{array}$ \\
\hline
\end{tabular}


$(\mathrm{F}=1.96, \mathrm{df}=20 / 160, \mathrm{p}<.05)$, and effects due to Units by Stimuli interaction $(F=3.09, \mathrm{df}=8 / 160, \mathrm{p}<.01)$. The effects due to Stimuli merely reflect the considerable differences in physical size of the stimuli. The effects due to Units of Measure indicate that, indeed, some units of measure resulted in different estimations than others. Specifically, estimates by the $\mathrm{cm}$ unit differed from those made using the larger units of measure. The Units by Stimuli interaction is due to the lower mean estimates by the $4 \mathrm{~cm}$ and 3 in units of measure for the 3.44 in stimulus relative to the estimates by these units for the other stimuli.

It is of interest to note that the mean estimates of all three stimuli, in terms of the inch segment, are lower than the corresponding mean estimates by the inch unit drawn from memory. To determine whether this difference was a stable one, the error component from the analysis of variance was used as an estimate of the standard error of the test statistic t. However, comparisons between estimates using an inch as a line segment and an inch drawn from memory resulted in $t$ values below significance $(p>.10)$.

\section{Diseussion}

The finding of a consistent underestimation using a relatively small unit of measure and a corresponding overestimation using relatively large units of measure, suggests that magnitude estimation may be bound $t$ the famliar unit of measure. This is also indicated by the finding of a relatively high degree of accuracy for the inch unit, regardless of response condition for the estimations of the two larger stimuli. Further, the second most accurate unit of measure for the 3.44 in stimulus was also the inch unit (presented as a segment). These results suggest an effect of past experience in magnitude estimation.

The result that there were no stable differences between the estimates made in terms of the inch unit drawn from memory and in terms of an inch line segment suggest that within the range of the lengths sampled in this study, the two conditions of responding are not essentially different.

\section{References}

Bolles, R. C., \& Bailey, D. E. Importance of object recognition in size constancy. J. exp. Psychol., 1956, 51, 222-225.

Churchill, A. V. Effect of mode of response on judgment of familiar size. J. exp. Psychol., 1962, 64, 198-199.

\section{Note}

1. This research was supported by a grant from the Rutgers University Research Council. 